\title{
Analysis of Energy Dissipation in Resistive Superconducting Fault Current Limiters for Optimal Power System Performance
}

\author{
Steven M. Blair, Student Member, IEEE, Campbell D. Booth, Nand K. Singh, \\ Graeme M. Burt, Member, IEEE, and Chris G. Bright
}

\begin{abstract}
Fault levels in electrical distribution systems are rising due to the increasing presence of distributed generation (DG) and this rising trend is expected to continue in the future. Superconducting fault current limiters (SFCLs) are a promising solution to this problem. This paper describes factors that govern the selection of the optimal SFCL resistance. The total energy dissipated in an SFCL during a fault is particularly important for estimating the recovery time of the SFCL; the recovery time affects the design, planning, and operation of electrical systems using SFCLs to manage fault levels. Generic equations for the energy dissipation are established, in terms of: fault duration, SFCL resistance, source impedance, source voltage, and fault inception angle. Furthermore, using an analysis that is independent of superconductor material, it is shown that the minimum required volume of superconductor varies linearly with SFCL resistance but, for a given level of fault current limitation and power rating, is independent of system voltage and superconductor resistivity. Hence, there is a compromise between a shorter recovery time, which is desirable, and the cost of the volume of superconducting material needed for the resistance required to achieve a shorter recovery time.
\end{abstract}

Index Terms-Distributed generation, fault current limitation, low-carbon, power system protection, superconducting fault current limiter.

\section{INTRODUCTION}

$\mathbf{S}$ UPERCONDUCTING fault current limiters (SFCLs) have been the subject of research and development for many years, and offer an attractive solution to the problem of rising fault levels in electrical distribution systems [1], [2], [3]. SFCLs can greatly reduce fault currents and the damage at the point of fault, and help improve the stability of a power system. This paper offers recommendations for the appropriate resistance of SFCLs when used to curb the fault current contribution from the connection of distributed generation (DG) to an existing distribution network. The term "SFCL resistance" in this paper is defined as the resistance of the SFCL device after the superconductor has quenched, but before it recovers.

This work was supported by the EPSRC and by Rolls-Royce Plc, and was carried out at the Rolls-Royce University Technology Centre at the University of Strathclyde.

Steven Blair, Campbell Booth, and Graeme Burt are with the Institute for Energy and Environment, Department of Electronic and Electrical Engineering, University of Strathclyde, Glasgow, G1 1XW, UK (e-mail: steven.blair@eee.strath.ac.uk).

Nand Singh was with the Institute for Energy and Environment, Department of Electronic and Electrical Engineering, University of Strathclyde, Glasgow, G1 1XW, UK. He is now with Vestas Wind Systems, Denmark.

Chris Bright is with Electrical Systems and Instrumentation, Rolls-Royce Strategic Research, Derby, DE24 8BJ.
Ideally, the resistance of an SFCL should be chosen to limit the fault current as much as possible. Not only does this benefit the electrical system through reduction in the potentially damaging effects of high fault currents, the primary purpose of the SFCL, but increasing the limitation of the fault current has a consequence of shortening the recovery time of the SFCL by reducing the energy dissipated in the resistance of the SFCL [4]. Furthermore, excessive heat dissipation may damage the SFCL and cause undue vaporization of the coolant [5], so increasing limitation is attractive from many perspectives.

Nevertheless, fault current limitation is subject to a compromise because a significantly limited fault current requires a high resistance SFCL and therefore a relatively higher amount of superconducting material, which increases capital costs. Also, electrical protection elsewhere in the system requires a high enough level of fault current in order to operate correctly through the ability to distinguish between faults and highly loaded situations [6].

Section II examines the relationship between SFCL resistance, voltage level, and energy dissipation using simulation. The results are analytically verified in Section III which establishes a generalized equation for energy dissipation, in terms of: the duration of the fault, SFCL resistance, source impedance, source voltage, and fault inception angle. Singleand three-phase analyses are presented. Furthermore, the volume of superconductor used in the SFCL must be sufficient to absorb the prospective energy dissipation [4]. Another requirement is that the dimensions of the superconductor must ensure that the SFCL discriminates between fault current, for which it must operate, and load current, for which it must not operate. The SFCL must not operate in response to transients such as transformer magnetic inrush. All of these considerations are included in a method for estimating the minimum volume of superconductor required. This method is independent of the type of material itself, and is described in Section IV.

\section{Selection of optimal SFCL Resistance By SIMULATION}

\section{A. Resistive SFCL model}

To simplify the analysis, a binary SFCL model is used: the SFCL has zero impedance before fault inception, but is assumed to reach its full resistance immediately when the fault occurs. This will yield a reasonably accurate estimation of the 


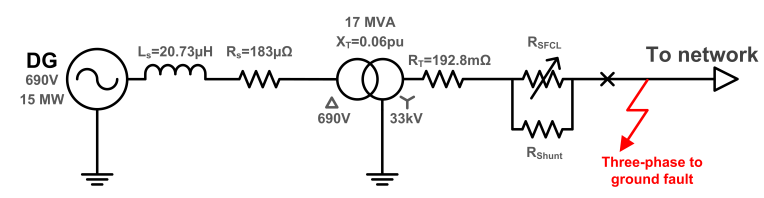

Fig. 1. DG branch with source impedance, transformer impedance, and an SFCL

reduction of steady-state RMS fault current (as defined in [7]), but will overestimate the reduction of the peak fault current; hence the following sections only comment on the effect an SFCL has on reducing the steady-state fault current. Although this model does not account for the development of SFCL resistance during a quench, tests with a more realistic SFCL model have shown that the results in this paper only differ by approximately $6 \%$, for a relatively long quench time.

\section{B. Comparison of system voltage level on energy dissipation}

Fig. 1 illustrates a representative DG connection to an existing power system. It is assumed that the fault level at the point of connection in the power system is already near the breaking capability of existing switchgear. An SFCL may be effective at several locations in the power system [1], [2], but this paper concentrates on a DG application in which the DG is the source of the fault level increase. Therefore, only one modification to the electrical network is required, that is, the installation of an SFCL in series with the DG, rather than installation of a number of SFCLs at different locations. Nevertheless, the analysis is relevant to SFCLs at any location. A three-phase to ground fault with negligible resistance is applied at the point where the DG is connected to the existing network.

The power system has been simulated in PSCAD/EMTDC [8], using impedance data from [9] such that the $\mathrm{X} / \mathrm{R}$ ratios - which are important for a fault study - are indicative of a typical system. The unrestricted steady-state fault current, i.e., without an SFCL, is approximately $1 \mathrm{kA}$ RMS per phase. Initially the shunt impedance, $R_{\text {shunt }}$, is ignored; this is explored in Section III-C. The total energy, $Q$, dissipated in each phase of the SFCL during the fault is calculated in the simulation using (1), where $t_{0}$ is the time of fault occurrence $(0.0 \mathrm{~s})$ and $t_{f}$ is the time the fault is cleared $\left(t_{f} \approx 0.1 \mathrm{~s}\right.$, depending on the current zero-crossing required for the circuit breaker to interrupt fault current).

$$
Q=\int_{t_{0}}^{t_{f}} i_{S F C L}(t)^{2} R_{S F C L} d t
$$

Fig. 2 illustrates the level of fault current reduction and the corresponding total energy dissipation in one phase of the SFCL for faults on the system. For the parameters used in the simulation, the following regions have been identified:

1) $R_{S F C L}<12 \Omega$ : the steady-state fault current is slightly reduced, reaching a magnitude of approximately 2.6 times load current, but the corresponding energy dissipation rises steeply as shown in Fig. 2.

2) $12 \Omega<R_{S F C L}<24 \Omega$ : the fault current reduces with increasing SFCL resistance, but the increasing resistance

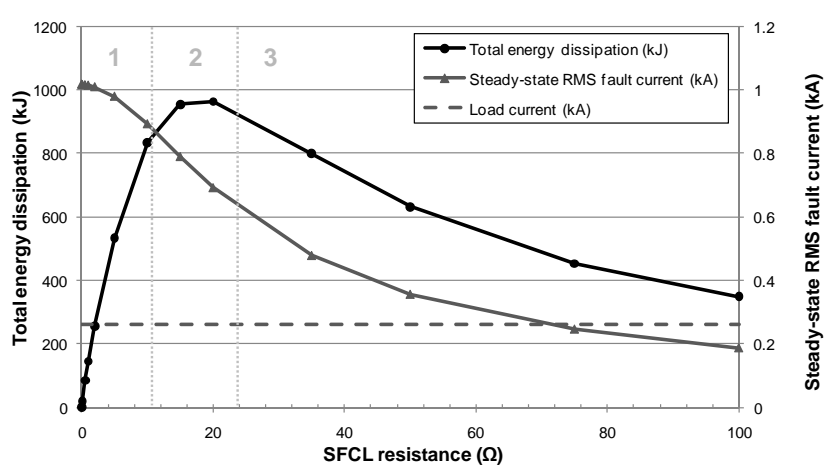

Fig. 2. Energy dissipation and fault current limitation for various SFCL resistance values (on $33 \mathrm{kV}$ side of DG transformer)

causes the energy dissipation to reach its maximum in this region. This large energy dissipation would lengthen the recovery time and so this range of SFCL resistances should be avoided. This result is in accordance with the maximum power transfer theorem [10]. The equivalent $33 \mathrm{kV}$ Thevenin source has an impedance of $18.7 \Omega$ (as derived from Fig. 1), so maximum energy dissipation in the SFCL occurs when its resistance equals the source impedance value.

3) $R_{S F C L}>24 \Omega$ : fault current continues to decrease with increasing SFCL resistance (almost linearly with resistance, as shown in Fig. 2), but the energy dissipation reduces. This is the most desirable region: relatively low fault current combined with low energy dissipation. It can be observed from Fig. 2 that an SFCL value of approximately $70 \Omega$ reduces the steady-state fault current to the same value as the maximum load current.

If the SFCL had been located at the $690 \mathrm{~V}$ side of the DG transformer instead of at $33 \mathrm{kV}$ then, for a given energy dissipation, the resistance values obey the law $R_{S F C L_{33 \mathrm{kV}}} \approx$ $R_{S F C L_{0.69 \mathrm{kV}}}(33 \mathrm{kV} / 0.69 \mathrm{kV})^{2}$. Therefore, far smaller resistance values are required for equivalent levels of fault current limitation; however the current-carrying capability of the SFCL is increased by a factor of $(33 \mathrm{kV} / 0.69 \mathrm{kV})$.

At either voltage level, the energy dissipation is approximately the same for a given level of fault current reduction relative to load current. Assuming an SFCL device is available at both voltage levels, there is a tradeoff between the quenched-state resistance of the superconductor and the current it must be rated to carry; this is explored further in Section IV. Although either SFCL would limit fault current, an SFCL at $690 \mathrm{~V}$ with a load rating of $15 \mathrm{MVA}$ would be required to have a full load current rating of over $12 \mathrm{kA}$ per phase which would present serious difficulties in design. By contrast, a $33 \mathrm{kV}$ SFCL would have a full load current of $250 \mathrm{~A}$ and would be easier to design, despite the higher voltage rating. However, operation at lower voltages leads to higher $\mathrm{AC}$ losses in the superconductor when in the superconducting state [11]. 


\section{ANALYSis OF OPTIMAL SFCL RESISTANCE VALUES}

\section{A. Analytical derivation of energy dissipation}

The SFCL resistance value for the maximum energy dissipation in the SFCL, as described in Section II, can be analytically verified. At the $33 \mathrm{kV}$ side of the interfacing transformer in Fig. 1 , the equivalent phase source impedance, $Z_{\text {source }}$, is:

$$
\begin{aligned}
Z_{\text {source }}= & R_{\text {source }}+j X_{\text {source }} \\
= & R_{s}\left(\frac{33 k V}{0.69 k V}\right)^{2}+R_{T} \\
& +j\left(L_{S} \omega\left(\frac{33 k V}{0.69 k V}\right)^{2}+X_{T} \frac{33 k V^{2}}{17 M V A}\right) \\
= & 0.6114+j 18.74 \Omega
\end{aligned}
$$

The circuit is characterized by the differential equation [3], [12]:

$$
\hat{V} \sin (\omega t+\alpha)=i(t) R+L \frac{d i(t)}{d t}
$$

where $\hat{V}=33 k V \times \sqrt{2} / \sqrt{3}, R=R_{\text {source }}+R_{S F C L}$, and $L$ is the inductive component of $Z_{\text {source }}$. The solution for the shortcircuit current, including both the symmetrical and asymmetrical components, can be stated as [13], [?]:

$$
i(t)=\frac{\hat{V}}{Z}\left[\sin (\omega t+\alpha-\phi)-\sin (\alpha-\phi) e^{\frac{-R t}{L}}\right]
$$

where $Z=\sqrt{R^{2}+L^{2} \omega^{2}}, \alpha$ is the point on the voltage waveform of fault occurrence, and $\phi=\tan ^{-1}(\omega L / R)$. The total energy dissipated in one phase of the SFCL during the fault, $Q$, is calculated using (1). Substituting (3) into (1) gives:

$Q=\int_{t_{0}}^{t_{f}} \frac{\hat{V}^{2} R_{S F C L}}{Z^{2}}\left[\sin (\omega t+\alpha-\phi)-\sin (\alpha-\phi) e^{\frac{-R t}{L}}\right]^{2}(A)$

A general algebraic solution to the integral can be stated as shown below, when substituting $t_{0}=0.0$ and $t_{f}$ :

$$
\begin{aligned}
Q= & \frac{\hat{V}^{2} R_{S F C L}}{R^{2}+\omega^{2} L^{2}}\left[\left(\frac{L e^{\frac{-R t_{f}}{L}}}{R^{2}+\omega^{2} L^{2}}\right)\right. \\
& \left(L \omega\left(\sin \left(\omega t_{f}+2(\alpha-\phi)\right)-\sin \left(\omega t_{f}\right)\right)\right. \\
& \left.+R\left(\cos \left(\omega t_{f}\right)-\cos \left(\omega t_{f}+2(\alpha-\phi)\right)\right)\right) \\
& +\frac{L}{R^{2}+\omega^{2} L^{2}}(R \cos (2(\alpha-\phi))-R-L \omega \sin (2(\alpha-\phi))) \\
& +\frac{L[\cos (2(\alpha-\phi))-1]}{4 R}\left(e^{\frac{-2 R t_{f}}{L}}-1\right) \\
& \left.+\frac{t_{f}}{2}+\frac{\sin \left(2\left(\omega t_{f}+\alpha-\phi\right)\right)+\sin (2(\alpha-\phi))}{4 \omega}\right]
\end{aligned}
$$

Hence, substituting $R=\left(R_{\text {source }}+R_{S F C L}\right)$ into (5) gives the value for the total energy dissipated in one phase of the SFCL, as a function of the SFCL resistance; all other parameters are constant. The root of the partial derivative of $Q$ (i.e., where $d Q / d R_{S F C L}=0$ ) determines the value of $R_{S F C L}$ resulting in maximum energy dissipation in the SFCL, $\hat{Q}$; for $\alpha=0$, this value is approximately $18.2 \Omega$. This differs from the magnitude of the source impedance $(18.7 \Omega)$ because the circuit is reactive and the maximum power transfer analogy is not strictly valid. Furthermore, $\alpha$ affects both the magnitude of the (decaying) DC offset in the fault current and the phase of the sinusoidal component; hence $\alpha$ has a somewhat complicated effect on the area under the fault current waveform, and the value of $R_{S F C L}$ resulting in $\hat{Q}$ consequently varies between approximately $18.1 \Omega$ and $18.9 \Omega$ as $\alpha$ is varied.

The equivalent value for an SFCL located at the $690 \mathrm{~V}$ side of the DG transformer is approximately $0.00794 \Omega$. This is in good agreement with the simulation results in Section II; the calculated values for energy dissipation differ by less than $2 \%$ from the simulation values. A small error is expected due to the delay associated with a circuit breaker interrupting fault current at a zero-crossing point, which is modelled in the simulation; in the analytical approach, the fault current is interrupted at a specified time regardless of the fault current value.

\section{B. Effect of fault inception angle}

Considering (4), if the asymmetrical component of the fault current is ignored (i.e., where $\alpha=\phi$ ), the equation for the total per-phase energy dissipation can be approximated as shown in (6).

$$
\begin{aligned}
Q & =\int_{t_{0}}^{t_{f}} \frac{\hat{V}^{2} R_{S F C L}}{Z^{2}} \sin ^{2}(\omega t) d t \\
& =\frac{\hat{V}^{2} R_{S F C L}}{Z^{2}}\left[\frac{t_{f}}{2}-\frac{\sin \left(2 \omega t_{f}\right)}{4 \omega}\right]
\end{aligned}
$$

Therefore the partial derivative of $Q$, with respect to $R_{S F C L}$, is (7); a root of (7) occurs when (8) is satisfied.

$$
\begin{gathered}
\frac{d Q}{d R_{S F C L}}=\frac{\hat{V}^{2}}{Z^{2}}\left[\frac{t_{f}}{2}-\frac{\sin \left(2 \omega t_{f}\right)}{4 \omega}\right]\left[1-\frac{2 R_{S F C L} R}{Z^{2}}\right] \\
\frac{2 R_{S F C L} R}{Z^{2}}=1
\end{gathered}
$$

Hence, with the approximation that $\alpha=\phi$, the energy dissipation is maximized when the SFCL resistance equals the source impedance magnitude, as shown in (9); as before, this is analogous to the maximum power transfer theorem [10]. Therefore, to reduce the fault current and the energy dissipation in an SFCL, the optimal SFCL resistance value is any value that is substantially larger than the magnitude of the source impedance.

$$
R_{S F C L}=\sqrt{R_{\text {source }}^{2}+L^{2} \omega^{2}}=\left|Z_{\text {source }}\right|
$$

The accuracy of this approximation is evaluated by considering the total energy dissipation in all three phases; the sum of the results of calculating Eq. (5) for each phase is compared with the value calculated using Eq. (10) (three times the value of (6)). Fig. 3 illustrates that there is only a small difference in the total energy dissipation; the approximation provides an accurate representation of the average energy dissipation per phase. Furthermore, Fig. 3 shows that the energy dissipation 


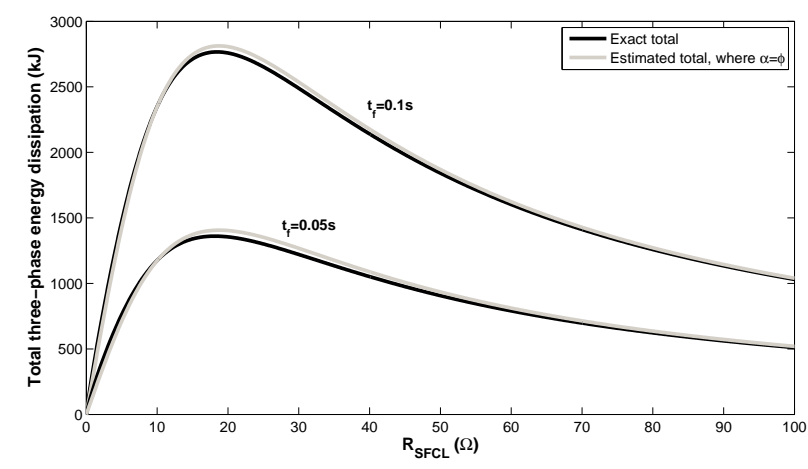

Fig. 3. Total three-phase energy dissipation: exact vs. approximation

varies approximately linearly with fault duration, which implies that faster acting protection is desirable to minimize the energy dissipation in the SFCL. This requirement may need to be taken into account for the integration of SFCLs with timegraded protection schemes in distribution systems, which can have relatively long trip times - in excess of one second.

$$
\begin{aligned}
Q_{\text {three-phase }} & \approx \frac{3 \hat{V}^{2} R_{S F C L}}{Z^{2}}\left[\frac{t_{f}}{2}-\frac{\sin \left(2 \omega t_{f}\right)}{4 \omega}\right] \\
& \approx \frac{V_{r m s}{ }^{2} R_{S F C L}}{Z^{2}}\left[t_{f}-\frac{\sin \left(2 \omega t_{f}\right)}{2 \omega}\right]
\end{aligned}
$$

\section{SFCL with resistive shunt}

Resistive SFCLs typically have a shunt resistance that is connected electrically in parallel with the SFCL, which may be bonded to the superconductor during manufacturing (to reduce hot-spots [1], [6]), or external to the cryogenic environment (to reduce the energy dissipated in the superconductor [14]), or both bonded and external [15]. The shunt impedance may also serve the purpose of intentionally reducing the effective resistance of the SFCL, by diverting fault current through the shunt resistance when the SFCL becomes resistive (with a value that is higher than the shunt resistance), to ensure that the fault current large is enough to be detected by existing protection relays [6]. It is assumed that the bonded type will provide very similar energy dissipation in the SFCL as for an SFCL without a shunt (as described in Sections II and III) because the total heat energy to be dissipated within the cryogenic chamber is the same. Eq. (5) can be modified to examine the effect of an external shunt resistance by replacing $R=R_{\text {source }}+R_{S F C L}$ with:

$$
R=R_{\text {source }}+\frac{1}{\frac{1}{R_{S F C L}}+\frac{1}{R_{\text {shunt }}}}
$$

and by recognizing that the current in the SFCL branch is:

$$
i_{S F C L}(t)=i_{\text {total }}(t) \frac{R_{\text {shunt }}}{R_{S F C L}+R_{\text {shunt }}}
$$

Fig. 4 illustrates the relationship between $R_{S F C L}, R_{\text {shunt }}, Q$ and the level of fault current limitation (in grayscale). The darkest regions offer the best reduction in steady-state fault current. A shunt with a small resistance, relative to the SFCL resistance,

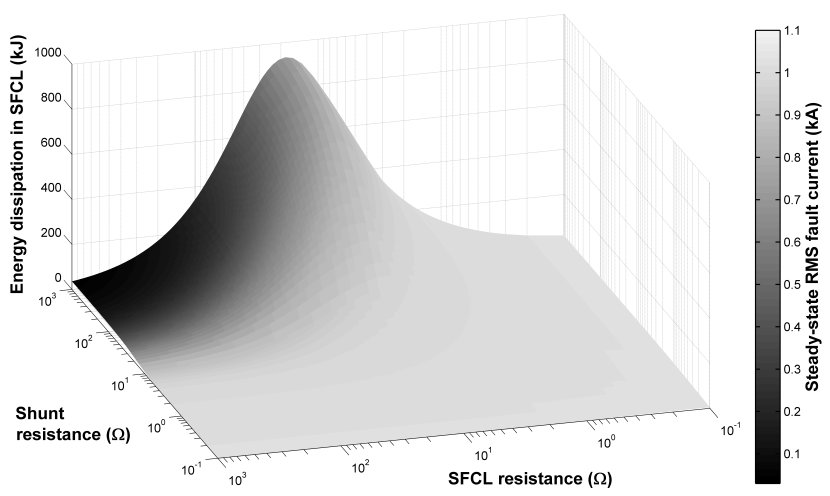

Fig. 4. Variation of SFCL energy dissipation and current limitation (in grayscale), with a resistive shunt

can significantly reduce the energy dissipation in the SFCL - and hence the recovery time - but only at the expense of a higher fault current value. The shunt would therefore carry the majority of the fault current, and would have to be designed accordingly, but this is considered feasible. The analytical results were confirmed by simulation.

\section{RELATIONSHIP OF SFCL POWER DISSIPATION TO MINIMUM VOLUME OF SUPERCONDUCTOR REQUIRED}

An SFCL must be able to absorb the prospective energy dissipation during a fault without failure, i.e., without exceeding a thermal limit. Consider a notional superconducting wire, or "unit", with a quenched resistance of $R_{\text {unit }} \Omega$ and an RMS current carrying capability of $I_{\text {unit }} \mathrm{A}$ (per phase). It is assumed that the current rating is based on the prospective temperature of the wire and the permissible time for which the temperature can be experienced, as dictated by $I_{\text {unit }}=\sqrt{\left(d T_{\text {unit }} C_{v} \text { Volume }_{\text {unit }}\right) /\left(R_{\text {unit }} t_{f}\right)}$, where $d T_{\text {unit }}$ is the temperature change and $C_{v}$ is the volumetric specific heat capacity of the superconductor. This assumes an adiabatic process but an alternative, non-adiabatic equation is derived in [4]. The required resistance rating of an SFCL can be obtained by connecting individual superconductor units in series; the current rating can be increased by connecting units in parallel, equivalent to increasing the cross-sectional area of the wire and thereby reducing the total resistance. Hence, the minimum number of superconductor units required per phase - a material-independent indication of the total superconductor volume - can be calculated using (12). Note that $I_{\text {limited }}$ depends upon $R_{S F C L}$. 


$$
\begin{aligned}
& \text { total units }=\text { units }_{\text {parallel }} \times \text { unit }_{\text {series }} \\
& =\left(\frac{I_{\text {limited }}}{I_{\text {unit }}}\right)\left(\frac{R_{S F C L} \text { units }}{R_{\text {parallel }}}\right) \\
& =\left(\frac{I_{\text {limited }}}{I_{\text {unit }}}\right)\left(\frac{R_{S F C L} I_{\text {limited }}}{R_{\text {unit }} I_{\text {unit }}}\right) \\
& =\text { units }_{\text {parallel }}{ }^{2}\left(\frac{R_{S F C L}}{R_{\text {unit }}}\right) \\
& =\frac{I_{\text {limited }}{ }^{2} R_{S F C L}}{I_{\text {unit }}{ }^{2} R_{\text {unit }}} \\
& =\frac{\text { total power dissipation }}{\text { unit power dissipation }}
\end{aligned}
$$

Eq. (12) implies that the minimum volume of superconductor required is proportional to the total power dissipation. This suggests that it is significantly more efficient, in terms of superconducting material, to limit the fault current as much as possible, as described in [16]. This is, of course, advantageous from the point of view of the electrical system because a lower fault current reduces the fault current interruption duty imposed on switchgear, and also the current carrying requirements of other equipment in the fault current paths. Higher SFCL resistances may also limit the voltage depression "upstream" of the SFCL from the fault and therefore reduce the upstream impact on other loads, and the potential for consequential and unwanted voltage-based protection during a disturbance.

However, to avoid spurious operation of the SFCL, the superconductor units must be arranged such that the effective critical current, $I_{c}$, of the SFCL is greater than load current, $I_{\text {load }}$, and the contribution from non-fault transients [6], [17]. Eq. (13) states the minimum $I_{c}$ for the required headroom value of $\lambda$.

$$
I_{c} \geq \lambda I_{\text {load }}
$$

If $I_{C_{\text {unit }}}$ is the critical current of one unit, $I_{c}$ can be calculated using (14):

$$
I_{c}=\text { units }_{\text {parallel }} \times I_{c_{\text {unit }}}
$$

Eq. (15) can be obtained by substituting (14) into (13):

$$
\begin{aligned}
\text { units }_{\text {parallel }} \times I_{c_{\text {unit }}} & \geq \lambda I_{\text {load }} \\
\text { units }_{\text {parallel }} & \geq \frac{\lambda I_{\text {load }}}{I_{c_{\text {unit }}}}
\end{aligned}
$$

Substituting (15) into (11) provides a more realistic estimate than (12) for the minimum number of superconductor units, as described by (16); the number of units required increases linearly with SFCL resistance.

$$
\text { total units } \geq\left(\frac{\lambda I_{\text {load }}}{I_{c_{\text {unit }}}}\right)^{2} \frac{R_{S F C L}}{R_{\text {unit }}}
$$

Fig. 5 compares this relationship with the initial estimate described by (12), where $I_{\text {load }}=250 \mathrm{~A}, R_{\text {unit }}=1 \Omega, I_{\text {unit }}=$

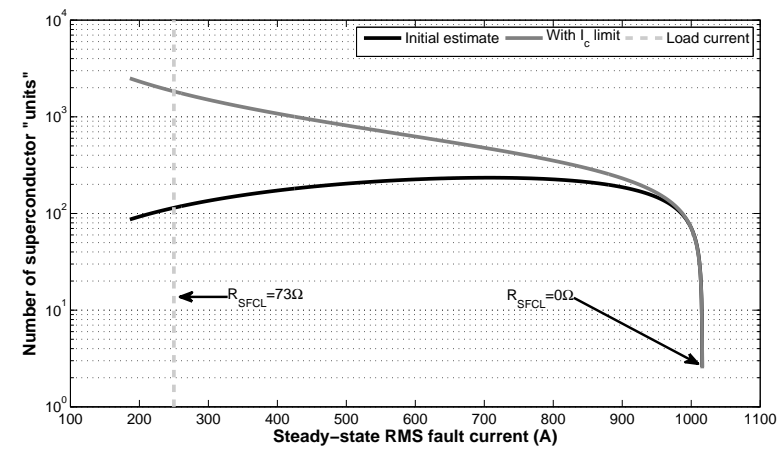

Fig. 5. Number of notional superconductor units required for a given level of fault current limitation

$200 \mathrm{~A}$, and $I_{c_{u n i t}}=100 \mathrm{~A}$. It is assumed that $\lambda=2$. This is based on fusing factors for fuses because the manufacture of superconducting wire may be subject to similar tolerances, but values of $\lambda$ such as 4 or 5 may be more appropriate [6]. When $I_{c}$ is not considered as in (12), Fig. 5 illustrates that the required number of superconductor units for a given fault current reduction is substantially underestimated. Furthermore, the number of superconductor units required does not depend on whether the SFCL is located at the $33 \mathrm{kV}$ or $690 \mathrm{kV}$ side of the transformer in Fig. 1 and, as noted in [16], [18], [19], [20], is independent of superconductor resistivity.

The manufacturing process of the superconductor may dictate additional constraints, such as the minimum crosssectional area of the wire. The SFCL must be rated to handle the peak limited fault current which may be substantially larger than the steady-state fault current; this may increase the required number of notional superconducting units because the thermal limit, dictated by $\int i(t)^{2} R_{S F C L} d t$, must not be exceeded.

\section{CONCLUSIONS}

Several studies advise on the optimal selection of the resistance of an SFCL, in terms of: reducing the impact on existing protection schemes [21], minimizing the power exchanged between regions of a power system during a fault [22], and analyzing the transient stability of induction machines [23] and synchronous generators [24], [25]. A multi-objective optimization technique is presented in [18]. References [4], [26] provide experimental results of the typical energy dissipation in resistive SFCLs. The focus of this paper is to thoroughly analyze the relationship between energy dissipation and SFCL resistance, and to highlight the compromises between the factors that affect the choice of SFCL resistance.

This paper has presented a guide for selecting the resistance value of a resistive SFCL, taking into account energy dissipation and the necessary volume of superconductor material. The resistance of the SFCL is proportional to the volume of the superconducting material. This paper has shown that the maximum energy dissipation occurs when the SFCL resistance approximately equals the magnitude of the source impedance, a result that would be expected from the maximum power transfer theorem. Therefore, to reduce energy dissipation and 
therefore shorten recovery times, the SFCL resistance should be much larger than the source impedance. A larger SFCL resistance requires a larger volume of superconducting material. Consequently, it has been shown that there is a compromise between lower energy dissipation, and therefore faster recovery times, and superconductor volume, which incurs capital costs.

Several issues remain for the integration of SFCLs within distribution networks, such as coordinating the fault current limiter for alternative system operating configurations, stability during distant faults where the DG should be stable and remain in service, and ensuring that protection operates correctly and quickly in networks with fault current limitation [17], [22]. These are the subjects of ongoing research.

\section{REFERENCES}

[1] M. Noe and M. Steurer, "High-temperature superconductor fault current limiters: concepts, applications, and development status," Superconductor Science and Technology, vol. 20, no. 3, pp. R15-R29, Mar. 2007.

[2] S. M. Blair, N. K. Singh, C. D. Booth, and G. M. Burt, "Operational control and protection implications of fault current limitation in distribution networks," in Universities Power Engineering Conference (UPEC), 2009, pp. 1-5.

[3] N. K. Singh, R. M. Tumilty, G. M. Burt, C. G. Bright, C. C. Brozio D. A. Roberts, A. C. Smith, and M. Husband, "System-Level Studies of a MgB2 Superconducting Fault-Current Limiter in an Active Distribution Network," IEEE Trans. Appl. Supercond., vol. 20, no. 2, pp. 54-60, Apr. 2010.

[4] I. N. Dul'kin, D. V. Yevsin, L. M. Fisher, V. P. Ivanov, A. V. Kalinov, and V. A. Sidorov, "Modeling Thermal Process in a Resistive Element of a Fault Current Limiter," IEEE Trans. Appl. Supercond., vol. 18, no. 1, pp. 7-13, Mar. 2008

[5] E. Thuries, V. Pham, Y. Laumond, T. Verhaege, A. Fevrier, M. Collet, and M. Bekhaled, "Towards the superconducting fault current limiter," IEEE Trans. Power Del., vol. 6, no. 2, pp. 801-808, Apr. 1991.

[6] R. Dommerque, S. Krämer, A. Hobl, R. Böhm, M. Bludau, J. Bock, D. Klaus, H. Piereder, A. Wilson, T. Krüger, G. Pfeiffer, K. Pfeiffer, and S. Elschner, "First commercial medium voltage superconducting fault-current limiters: production, test and installation," Superconductor Science and Technology, vol. 23, no. 3, p. 034020, Mar. 2010.

[7] IEC, "IEC 60909-0 Short-circuit currents in three-phase systems: Part 0 : Calculation of currents," 2001

[8] Manitoba HVDC, "PSCAD." [Online]. Available: https://pscad.com/products/pscad/

[9] "Distribution Long Term Development Statement for SP Distribution LTD," SP Transmission \& Distribution, Tech. Rep., 2003.

[10] J. W. Nilsson and S. Riedel, Electric Circuits, 7th ed. Prentice Hall, 2004.

[11] P. Tixador, "Superconducting current limiters-some comparisons and influential parameters," vol. 4, no. 4, pp. 190-198, 1994.

[12] D. G. Duffy, Advanced engineering mathematics with MATLAB. CRC Press, 2003

[13] C. Poulain, F. Dumas, and B. de Metz-Noblat, "Calculation of shortcircuit currents," Schneider Electric Cahiers Techniques, no. 158, 2005

[14] C. Schacherer, J. Langston, M. Steurer, and M. Noe, "Power Hardwarein-the-Loop Testing of a YBCO Coated Conductor Fault Current Limiting Module," IEEE Trans. Appl. Supercond., vol. 19, no. 3, pp. 18011805, Jun. 2009

[15] L. Martini, M. Bocchi, M. Levati, and V. Rossi, "Simulations and Electrical Testing of Superconducting Fault Current Limiter Prototypes," IEEE Trans. Appl. Supercond., vol. 15, no. 2, pp. 2067-2070, Jun. 2005.

[16] H. Shimizu, Y. Yokomizu, M. Goto, T. Matsumura, and N. Murayama "A study on required volume of superconducting element for flux flow resistance type fault current limiter," IEEE Trans. Appl. Supercond., vol. 13, no. 2, pp. 2052-2055, Jun. 2003.

[17] S. M. Blair, A. J. Roscoe, C. D. Booth, G. M. Burt, A. Teo, and C. G. Bright, "Implications of fault current limitation for electrical distribution networks," in 10th IET International Conference on Developments in Power System Protection. IET, 2010.

[18] R. Sharifi and H. Heydari, "Multiobjective Optimization for HTS FaultCurrent Limiters Based on Normalized Simulated Annealing," IEEE Trans. Appl. Supercond., vol. 19, no. 4, pp. 3675-3682, Aug. 2009.
[19] P. Tixador, L. Porcar, E. Floch, D. Buzon, D. Isfort, D. Bourgault, $\mathrm{X}$. Chaud, and R. Tournier, "Current limitation with bulk Y-Ba-Cu-O," IEEE Trans. Appl. Supercond., vol. 11, no. 1, pp. 2034-2037, Mar. 2001.

[20] S. Kalsi and A. Malozemoff, "HTS fault current limiter concept," in IEEE Power Engineering Society General Meeting, 2004, pp. 14261430 .

[21] H. Kameda and H. Taniguchi, "Setting method of specific parameters of a superconducting fault current limiter considering the operation of power system protection-resistance-type and rectifier-type SFCLs in overhead transmission systems," IEEE Trans. Appl. Supercond., vol. 9, no. 2, pp. 1355-1360, Jun. 1999.

[22] B. Sung, D. Park, J. Park, and T. Ko, "Study on Optimal Location of a Resistive SFCL Applied to an Electric Power Grid," IEEE Trans. Appl. Supercond., vol. 19, no. 3, pp. 2048-2052, 2009.

[23] A. S. Emhemed, R. M. Tumilty, N. K. Singh, G. M. Burt, and J. R. McDonald, "Analysis of Transient Stability Enhancement of LVConnected Induction Microgenerators by Using Resistive-Type Fault Current Limiters," IEEE Trans. Power Syst., vol. 25, no. 2, pp. 885893, May 2010.

[24] M. Tsuda, Y. Mitani, K. Tsuji, and K. Kakihana, "Application of resistor based superconducting fault current limiter to enhancement of power system transient stability," IEEE Trans. Appl. Supercond., vol. 11, no. 1, pp. 2122-2125, Mar. 2001.

[25] B. C. Sung, D. K. Park, J.-W. Park, and T. K. Ko, "Study on a Series Resistive SFCL to Improve Power System Transient Stability: Modeling, Simulation, and Experimental Verification," IEEE Trans. Ind. Electron., vol. 56, no. 7, pp. 2412-2419, Jul. 2009.

[26] C. Schacherer, A. Kudymow, and M. Noe, "Dissipated energy as a design parameter of coated conductors for their use in resistive fault current limiters," Journal of Physics: Conference Series, vol. 97, no. 1, p. 012193 , Feb. 2008.

Steven M. Blair (S'09) received the M.Eng. degree (with distinction) in Computer and Electronic Systems in 2008 from the University of Strathclyde, Glasgow, U.K., where he is currently pursuing the Ph.D. degree in electrical engineering.

His research interests include power system protection, fault current limitation, marine electrical systems, communications, and real-time simulation.

Campbell D. Booth received the B.Eng. and Ph.D. degrees in electrical and electronic engineering from the University of Strathclyde, Glasgow, U.K. He is currently a Senior Lecturer with the Institute for Energy and Environment, Department of Electronic and Electrical Engineering, University of Strathclyde.

His research interests include power system protection; plant condition monitoring and intelligent asset management; applications of intelligent system techniques to power system monitoring, protection, and control; knowledge management; and decision support systems.

Nand K. Singh (M'04) received the M.Eng. degree (with distinction) in electronic and electrical engineering with a specialization in electric drives and power electronics from the Belarusian National Technical University, Minsk, Belarus, in 1999, and the Ph.D. degree from the University of Strathclyde, Glasgow, U.K., in 2007.

He was a Postdoctoral Research Fellow with the Institute for Energy and Environment, University of Strathclyde, where he worked for two years until April 2009. He is now with Vestas Wind Systems, Denmark. His research interests include power system modelling and simulation, protection, and use of power electronics in both power system interface and drive systems.

Graeme M. Burt (M'95) received the B.Eng. degree in electrical and electronic engineering and the Ph.D. degree following research into fault diagnostic techniques for power networks from the University of Strathclyde, Glasgow, U.K., in 1988 and 1992, respectively. 
He is currently the Chair in Power Systems in the Institute for Energy and Environment, University of Strathclyde. He is also currently the Director of the University Technology Centre in electrical power systems sponsored by Rolls-Royce, Coventry, U.K. His current research interests include the areas of protection and control for distributed generation, power system modeling and simulation, and active distribution networks.

Chris G. Bright received the B.S. degree in electrical engineering and the M.S. degree in induction motor control from the University of Southampton, Southampton, U.K.

He worked for 22 years in the U.K. electricity supply industry before joining Rolls-Royce, Derby, U.K., as an Electrical Systems Specialist in the Strategic Research Centre, where he has worked for three years. 